\title{
Análise midiática sobre o futebol feminino no Brasil: elementos didáticos para a Educação Física no ensino médio
}

\section{RESUMO}

O objetivo desse estudo foi compreender a produção discursiva da revista PLACAR sobre o futebol feminino no Brasil e produzir conhecimentos que possam ser utilizados para fomentar esse debate nas aulas de Educação Física no Ensino Médio. A partir de uma pesquisa documental, em 1017 periódicos, localizados na biblioteca do Museu do Futebol em São Paulo, foi realizada a análise de conteúdo para identificar unidades de significado sobre o futebol feminino. O discurso sobre a mulher no futebol está fortemente marcado pela proibição e discriminação. Apesar disso, graças a inúmeras atletas e aos ideais feministas, as jogadoras estão gradativamente conseguindo espaço e respeito. Temas como a sexualização da mulher no futebol, a luta pela igualdade de gênero nessa modalidade esportiva, a existência de jogos e campeonatos de futebol feminino e as diversas profissões que são ocupadas por mulheres nessa prática corporal podem ser problematizados nas aulas de Educação Física.

PALAVRAS-CHAVE:Produção discursiva; Futebol feminino; Educação física; Ensino médio
Mariana Gomes de Oliveira

Curso de Eletrônica integrado ao Ensino

Médio

Instituto Federal de São Paulo, Diretoria de Elétrica, São Paulo, Brasil ana7mago@gmail.com

는tps://orcid.org/0000-0002-4987-3828

\section{Daniel Teixeira Maldonado}

Doutor em Educação Física Instituto Federal de São Paulo, Diretoria de Humanidades, São Paulo, Brasil danieltmaldonado@yahoo.com.br D https://orcid.org/0000-0002-0420-6490 
Media analysis on women's soccer in Brazil: didactic elements for Physical Education in high school

\begin{abstract}
The objective of this study was to understand the discursive production of PLACAR magazine on women's football in Brazil and to produce knowledge that can be used to foster the discussion during Physical Education in High School. Based on a documentary research, in 1017 periodicals, located in the library of the Museum of Football in São Paulo, a content analysis was carried out to identify the units of meaning produced about women's football. Discursive production about women in football is strongly marked by prohibition and discrimination. Despite this, thanks to countless athletes and feminist ideals, the players are gradually gaining space and respect. Themes such as the sexualization of women in football, the struggle for gender equality in this sport, the existence of games and championships for female football and the various professions that are occupied by women in this corporal practice can be problematized in Physical Education classes.
\end{abstract}

KEYWORDS:Discursive production; Women's football; Physical education; High school

Análisis mediático sobre fútbol femenino en Brasil: elementos didácticos para la Educación Física en la escuela secundaria

\title{
RESUMEN
}

El objetivo de este estudio fue comprender la producción del discurso de la revista PLACAR sobre el fútbol femenino en Brasil y generar conocimiento que pueda usarse en las clases de Educación Física en la Escuela Secundaria. Basado en una investigación documental, en 1017 revistas, ubicadas en la biblioteca del Museo del Fútbol en São Paulo, se realizó un análisis de contenido. El discurso sobre las mujeres en el fútbol está fuertemente marcado por la prohibición y la discriminación. A pesar de esto, gracias a innumerables atletas e ideales feministas, las jugadoras están ganando gradualmente espacio y respeto. Temas como la sexualización de las mujeres en el fútbol, la lucha por la igualdad de género en este deporte, la existencia de juegos y campeonatos para el fútbol femenino y las diversas profesiones que ocupan las mujeres en esta práctica corporal se pueden discutir en las clases de Educación Física.

PALABRAS-CLAVE:Producción discursiva; Fútbol femenino; Educación física; Escuela secundaria 


\section{INTRODUÇÃO}

O universo do futebol caracteriza-se por ser, desde sua origem, um espaço eminentemente masculino, refletindo os valores socioculturais estabelecidos pela sociedade. Dessa forma, a entrada das mulheres em campo transformou essa realidade. As reações decorrentes dessa nova ordem social expressam muito bemas relações de gênero presentes em cada comunidade, já que quanto mais machista, ou sexista, ela for, mais exacerbadas serão as dificuldades das mulheres praticarem a respectiva modalidade esportiva (FRANZINI, 2005).

Nesse contexto, após anos de proibição da realização de competições oficiais do futebol disputado por mulheres no Brasil, devido ao discurso que essa prática poderia "masculinizar" as atletas, acabar com a essência feminina ou deixar marcas no corpo que inviabilizariam a maternidade, na década de 1980 surgem vários times femininos, clubes criam suas equipes e alguns campeonatos adquirem visibilidade no calendário esportivo nacional (GOELLNER, 2005).

Todavia, Mourão e Morel (2005) e Souza e Knijnik (2007) analisaram as narrativas da mídia esportiva sobre o futebol feminino e concluíram que a produção midiática reforçou o discurso de fragilidade da mulher, além de espetacularizar o corpo feminino, dando mais valor aos aparatos físicos e comportamento das atletas do que para as suas habilidades como jogadoras do respectivo esporte.

Mais recentemente, Salvini e Marchi Júnior (2016) narraram a história do futebol feminino contada pela revista PLACAR entre os anos 1980 e 2010. A autora e o autor analisaram todas os periódicos disponíveis online desse período, selecionando 23 revistas pertinentes ao assunto. Os resultados evidenciaram que as reportagens publicadas na década de 1980 pela revista foi afetada pela liberação da prática do futebol feminino no Brasil. A década de 1990 foi marcada por um processo de dicotomia entre jogadoras com habilidade esportiva e as que utilizam o meio como um trabalho "não esportivo", pois são modelos e atrizes, já que o corpo tido como padrão de beleza se aproximava das modelos e não de jogadoras federadas, tornando o espaço midiático "como uma vitrine social". Entre os anos 2000 e 2010, as publicações reforçavam o retrato de um futebol "amadurecido e resiliente", que descrevia competições e também da trajetória de Marta, mas tem em vista as dificuldades da modalidade.

Portanto, a literatura da área tem mostrado que a produção midiática sobre o futebol feminino no Brasil se encontra em uma corda bamba, ancorada entre a erotização do corpo da mulher e o seu talento esportivo na modalidade. 
Ao fazer essa análise durante um trabalho organizado nas aulas de Educação Física no Ensino Médio, realizamos uma visita ao Museu do Futebol, localizado no município de São Paulo, e pesquisamos 1027 periódicos da Revista PLACAR na biblioteca do espaço, com edições publicadas entre 1980 e 2020.

$\mathrm{Na}$ perspectiva de ampliar a análise realizada por Salvini e Marchi Júnior (2016), que pesquisaram as edições virtuais do respectivo periódico, objetivamos com esse estudo compreender a produção discursiva da revista Placar sobre o futebol feminino no Brasil e, após essa análise, produzir conhecimentos que possam ser utilizados para fomentar o debate sobre as relações de gênero nas práticas corporais durante as aulas de Educação Física Escolar no Ensino Médio.

\section{MÉTODO}

Foi realizada uma pesquisa documental, na qual se utiliza documentos como fonte de informação (FLICK, 2009). Uma diversidade de fontes podem ser utilizadas na realização deste tipo de pesquisa, sejam elas sonoras, visuais ou impressas (LAVILLE; DIONNE, 1999). No presente estudo, utilizamos como fonte de informações todas as edições da revista PLACAR existentes na biblioteca do Museu do Futebol editoradas entre o ano de 1980 e 2020, exceto aquelas publicadas entre 1987 e 1989. Devido ao fechamento do museu e a quarentena decretada por conta da pandemia do corona vírus, esses três anos não foram analisados. A coleta dos dados ocorreu entre os meses de fevereiro e março de 2020.

Ao final do processo de pesquisa, 1017 revistas publicadas entre 1980 e 2020 foram consultadas e 42 foram selecionadas como base de dados, a partir de 54 reportagens que versavam sobre o futebol feminino.

No quadro 1, é possível identificar a quantidade de revistas e de reportagens sobre o futebol feminino utilizadas.

Quadro 1 - Revistas analisadas sobre futebol feminino existentes na revista Placar.

\begin{tabular}{|c|c|c|c|}
\hline CATEGORIAS & REVISTAS & $\begin{array}{c}\text { REPORTAGENS } \\
\text { UTILIZADAS }\end{array}$ & $\begin{array}{c}\text { ANO DE } \\
\text { PUBLICAÇÃO }\end{array}$ \\
\hline $\begin{array}{c}\text { Sexualização da } \\
\text { mulher na } \\
\text { sociedade e...no } \\
\text { futebol }\end{array}$ & 15 revistas & $\begin{array}{c}18 \text { reportagens relacionadas } \\
\text { ao futebol feminino }\end{array}$ & $1991-2004$ \\
\hline $\begin{array}{c}\text { Luta pela igualdade } \\
\text { de gênero no } \\
\text { futebol }\end{array}$ & 11 revistas & $\begin{array}{c}16 \text { reportagens relacionadas } \\
\text { ao futebol feminino }\end{array}$ & $1984-2019$ \\
\hline
\end{tabular}




\begin{tabular}{|c|c|c|c|}
\hline $\begin{array}{c}\text { Jogos e } \\
\text { campeonatos de } \\
\text { futebol feminino }\end{array}$ & 8 revistas & $\begin{array}{c}\text { 11 reportagens relacionadas } \\
\text { ao futebol feminino }\end{array}$ & $1985-2019$ \\
\hline $\begin{array}{c}\text { A mulher na área } \\
\text { esportiva no } \\
\text { futebol }\end{array}$ & 8 revistas & $\begin{array}{c}\text { 9 reportagens relacionadas } \\
\text { ao futebol feminino. }\end{array}$ & $1985-2019$ \\
\hline
\end{tabular}

Fonte: Elaborado pelos autores.

Para interpretar os dados empregamos a técnica de análise de conteúdo (LAVILLE; DIONNE, 1999), procurando identificar as unidades de significado e as categorias relacionadas com a participação feminina no futebol.

Assim como Neira (2014), que analisou a prática de skate em uma praça da cidade de São Paulo, com o intuito de possibilitar a circulação das informações obtidas a respeito dessa prática corporal e dos seus representantes, transformando esses conhecimentos em temas que podem ser debatidos nas aulas de Educação Física Escolar, realizamos essa pesquisa com a mesma intencionalidade.

\section{RESULTADOS E DISCUSSÃO}

A partir do estudo e da análise de 54 reportagens que continham matérias diretamente relacionadas ao futebol feminino e, em alguns casos, as mulheres dentro do meio futebolístico, encontramos quatro grandes temas que estão divididos nas seguintes categorias: sexualização da mulher na sociedade e.... no futebol, luta pela igualdade de gênero no futebol, jogos e campeonatos femininos de futebol e a mulher na área esportiva do futebol.

\section{Sexualização da mulher na sociedade e.... no futebol}

Ao falar de sexualização da mulher, podemos dividir o tópico em dois comportamentos. $\mathrm{O}$ primeiro está relacionado com a sociedade patriarcal, que atribui a mulher características vistas como inerentes a ela pelo seu gênero e cria uma imagem de mulher ideal, isto é, doce, bonita, bem-humorada, fisicamente fraca e etc. E também a sexualização erótica, que põe a figura feminina e seu corpo representados como objeto, permitindo então a admiração, uso e propriedade do mesmo. Sabendo disso, dividimos o nosso tema em três temas dentro dessa categoria, sendo eles"a sexualização do corpo e imposição do mesmo como espetáculo", "padrão de beleza imposto" e "homofobia atrelada ao futebol feminino". 
Pensando nisso, abaixo estão indicadas as matérias e suas respectivas revistas que estão relacionadas ao tema em tela.

Quadro 2 - Pesquisas relacionadas com a sexualização da mulher no futebol

\begin{tabular}{|c|c|c|}
\hline Reportagens & Edição das revistas & $\begin{array}{c}\text { Ano de } \\
\text { publicação }\end{array}$ \\
\hline Um Time só de estrelas & $\mathrm{N}^{\circ} 593$ & 1981 \\
\hline A bela... E as Feras & $\mathrm{N}^{\circ} 701$ & 1983 \\
\hline Isis desafia Radar & $\mathrm{N}^{\circ} 727$ & 1984 \\
\hline Artilheira Manequim & $\mathrm{N}^{\circ} 742$ & 1984 \\
\hline Este sim é o futebol arte & Jan a Março & 1983 \\
\hline Balé é coisa de atleta & $\mathrm{N}^{\circ} 761$ & 1984 \\
\hline Craque garçonete & $\mathrm{N}^{\circ} 769$ & 1985 \\
\hline As garotas batem um bolão & $\mathrm{N}^{\circ} 1106$ & 1995 \\
\hline Invasão de privacidade & $\mathrm{N}^{\circ} 1109$ & 1995 \\
\hline Cuidado, Piranhas! & $\mathrm{N}^{\circ} 1114$ & 1996 \\
\hline Mulheres Maravilha & $\mathrm{N}^{\circ} 1119$ & 1996 \\
\hline Valeu meninas, e agora? & $\mathrm{N}^{\circ} 1119$ & 1996 \\
\hline Time das massagistas & $\mathrm{N}^{\circ} 1119$ & 1996 \\
\hline O futebol engatinha & $\mathrm{N}^{\circ} 1127$ & 1997 \\
\hline Top de bola & $\mathrm{N}^{\circ} 1155$ & 1999 \\
\hline Meninas Superpoderosas & $\mathrm{N}^{\circ} 2 . \mathrm{OUT}$ & 2001 \\
\hline Apanhamos de mulher... e gostamos & $\mathrm{N}^{\circ} 2 . \mathrm{OUT}$ & 2001 \\
\hline Ela é ouro puro & $\mathrm{N}^{\circ} 1275$ & 2004 \\
\hline
\end{tabular}

Fonte: Elaborado pelos autores.

O processo de sexualização patriarcal da mulher pode ser caraterizado como a atribuição dos modos que ela deve ter e que são tidos como inevitáveis devido ao seu gênero. Embora o futebol feminino tenha sido regulamento e permitido no Brasil novamente na década de 1980, as pessoas mantinham um pensamento idealizado da mulher dona de casa. Essa mulher idealizada tem objetivo de procriar, de cuidar da casa e do marido, e da sua estética pessoal. Ela também deveria atender a padrões de beleza e de costumes.

As jogadoras, portanto, estavam atreladas a esse raciocínio, logo essas características eram cobradas delas. Um exemplo desse conteúdo está contido na entrevista com a jogadora americana 
Heather Mitts, "Ela é ouro puro". Nessa entrevista, feita por uma jornalista da revista Playboy, perguntam para Heather sobre sua vida amorosa, se ela se interessa por algum jogador brasileiro, se já recebeu cantadas, outra pergunta referente ao atual namorado. Essas indagações a colocam na posição de mulher que deve procriar, e portanto, sua vida amorosa é vista como pauta.

O problema dessa situação está em que, ao fugir da pertinência da entrevista, que seria sobre a recente conquista de dois ouros na campanha americana do futebol feminino, ou qualquer outro assunto relevante a sua profissão, deixa-se de entrevistar uma jogadora, e passa-se a entrevistar uma mulher. Partindo desse ponto, as perguntas são carregadas de ideologias, como a de que a mulher deve ser delicada, como pode-se observar na pergunta "como é ser tão bonita e jogar tão duro?"

Outra sexualização frequente é a do corpo feminino. Ele é visto como espetáculo, e ao expô-lo de forma sensual, denota-se a ele uma imposição de um padrão e a um objeto de domínio público, que pessoas podem ver e comentar. Tratando-o dessa forma, algumas empresas e a mídia conseguiam atrair atenção e ganhar dinheiro em cima do corpo de diversas mulheres, incluindo jogadoras.

"Um time só de estrelas" é uma reportagem referente a mulheres que eram atrizes e admiradas por sua estética. A reportagem coloca foto das jogadoras com seus uniformes, e também descreve a roupa como "justa e decotada". Atribui adjetivos as mesmas como "soccer sex stars, fantástica, moça da banana", etc.

Ao relacionar a foto de uma mulher de biquíni com sua profissão, nós tiramos seu mérito como jogadora e voltamos nossa atenção somente para o seu corpo, objetificando e diminuindo sua atuação em campo, como mostrado em "Craque garçonete", que possui uma foto de tamanho considerável da jogadora Janet Van Soest de biquíni, e ao lado informações pessoais e muito pouco sobre sua profissão.

A reportagem "invasão de privacidade" é sobre o time Limelight soccer models, formado por modelos e ex-capas da revista Playboy. O conteúdo é recheado de fotos das jogadoras seminuas, seja no vestiário, ou no quarto das meninas em uma guerra de travesseiros. Ela atende a fetiches masculinos relacionados ao corpo da mulher, que por sua vez, se sente sortuda com a atenção, pois a beleza é o único modo de ter voz nesse campo. Isso é demonstrado pelo desejo de ser capa da Playboy, que por sinal a jogadora Lyliá Virna possuía. Esse time era administrado por um empresário que fornecia uma vida luxuosa as jogadoras e seus jogos eram vendidos como atrações em eventos.

Outra vertente da sexualização do corpo da mulher é a criação de um padrão de beleza, onde se determina que meninas devem ter certas características para serem belas. Essa cobrança fica clara 
em reportagens como "Artilheira manequim", "A bela... E as feras" e outras que citam as medidas corporais das jogadoras.

Em “Artilheira manequim" Eliane Maria Duarte defende que "A beleza é fundamental às jogadoras" e que "sendo bonita, a galera perdoa quando a gente perde um gol”. Já em "A bela... e as feras", tem fotos das jogadora Bel e Sara. Abaixo do título bela, medidas corporais de Bel, uma jogadora branca, são expostas. Assim, aparecem expressões como "brilha tanto na bola como na graça" e "balançou os quadris num movimento obrigatoriamente sensual". Abaixo do título as feras, a jogadora Sara é referenciada, sendo ela negra e atleta do time Bangu. A fotografia mostra apenas o rosto da jogadora, como que chamando atenção para a cor da sua pele e para o corte de cabelo. Para completar o cunho racista da reportagem, eles utilizam as expressões "selvagem agressão", "perigosas meninas" e "e que as feras voltem para as jaulas".

Essa imposição estética vai além da narração da mídia, como no caso de "Time das massagistas", onde menciona que o técnico Ribeiro apenas escalava meninas bonitas.

Esses padrões visuais também estimulam a homofobia, do modo que jogadoras eram discriminadas, pois jogar estava atrelado a homossexualidade. Dentro do espaço futebolístico, esse tópico era frequentemente levantado entre as jogadoras.

Em "meninas superpoderosas" pode-se ler a seguinte informação "[...] há quem concorde com a beleza como critério. É que a (falsa) imagem de esporte de sapatão incomoda, e muito, a técnicos e jogadoras”. Na reportagem, está exposta uma foto de Angela Silva e na descrição aponta seu cabelo "Joãozinho". Em seguida, uma fala da jogadora "quem quer ser modelo que vá para um desfile". Logo abaixo, a foto da jogadora Heloísa acompanha sua opinião "não tenho nada contra" lésbicas em campo, desde que ela possa "se trocar no vestiário sem ser assediada". A jogadora ressalva que isso nunca aconteceu". Em outra reportagem, "Valeu meninas, e agora?", também aparecea frase "superar os traumas de um passado recheado de histórias de homossexualismo".

Estudos qualitativos, como aquele publicado por Souza, Capraro e Moraes e Silva (2017), enfatiza a realidade do processo de sexualização da mulher no futebol. Ao entrevistar Marina Toscano e Dayane de Fátima, atletas da respectiva modalidade esportiva, a autora e os autores mostram os padrões de gênero e estética impostos tanto pela sociedade, quanto pela mídia, para as jogadoras, como podemos ver no relato de Marina “toda vez que nós íamos dar entrevista, eu tinha que estarlinda, eu tinha que estar arrumada, eu tinha que estar perfeita nos programas de televisão, porque as pessoas queriam ver uma Marina que eu não era em campo”. Já a jogadora Dayane, quando perguntada se já sofreu preconceito durante sua carreira, responde "olha, eu não sofri porque eu sempre mantive a aparência que eu quis. Eu sempre tive cabelo comprido, eu sempre me 
vesti bem. Mas assim, eu tenho amigas que sofreram muito preconceito pelo fato de ter o cabelo curto, pelo fato de não se vestir bem, pelo fato de deixar decair a imagem”.

Essa imposição de imagem está relacionada a idealização da mulher e também a homofobia, porque se a mulher não possui um traço considerado feminino, como os cabelos longos, ela automaticamente é criticada. Além disso, a pressão por certos padrões de beleza e gênero não vem somente da mídia. Na pesquisa, Dayane relatou o fato de que a própria Confederação Brasileira de Futebol trabalhou para adequar os corpos e a imagem das atletas aos padrões desejados pela mídia, aconselhando que as meninas deixassem seus cabelos mais compridos e trazendo para concentração da seleção brasileira profissionais de beleza, como manicures, pedicures e cabeleireiros. Marina narrou um episódio protagonizado pela Federação Paulista de Futebol em 2007. A entidade contratou modelos profissionais para atuarem no campeonato paulistadaquele ano, na tentativa de elevar o padrão estético da competição (SOUZA; CAPRARO; MORAES e SILVA, 2017).

Nesse contexto, Teixeira e Caminha (2013) pesquisaram o preconceito de gênero no futebol feminino, através da revisão sistemática. Os resultados do estudo mostraram que os padrões, tanto de comportamento quanto de beleza, criaram um ideal do significado de ser mulher, e quando não atendidos, a jogadora era masculinizada perante a sociedade. Esse raciocínio dificultou a evolução do futebol feminino no Brasil, pois as desconfianças em relação à presença da mulher no esporte estiveram culturalmente associadas ao medo de vulgarizar o corpo feminino, ou seja, de torná-lo masculino por meio do esforço físico intenso. Portanto, o preconceito de gênero no futebol tem raízes históricas e culturais, provocando segregação, exclusão e o cerceamento da mulher em determinadas práticas corporais consideradas femininas, limitação na escolha das práticas esportivas, a erotização do corpo feminino e vigilância sobrea identidade de gênero das atletas.

Durante a nossa análise sobre a sexualização das atletas de futebol na Revista PLACAR, mostramos durante as entrevistas com as jogadoras, as perguntas realizadas se direcionavam para assuntos não pertinentes ao futebol, mas sim para questões da vida pessoal das mulheres, principalmente relacionadas com a beleza e o comportamento sexual, enfatizando o preconceito de gênero existentes na respectiva modalidade esportiva.

\section{Luta pela igualdade de gênero no futebol}

A luta na sociedade pela igualdade de gênero no âmbito salarial, empregatício, e também por oportunidades está viva todos os dias no mundo contemporâneo. Essas diferenças também estão presentes no futebol, que além de ser considerado um esporte masculino, só abriu espaço para as 
mulheres na década de 1980 no Brasil. Nessa categoria, as reportagens vão mostrar a luta das mulheres por visibilidade, salário, oportunidades e respeito.

Abaixo, encontra-se um quadro que relaciona as matérias que abrangem esse assunto e suas respectivas revistas.

Quadro 3 - Reportagens relacionadas com a igualdade de gênero no futebol

\begin{tabular}{|c|c|c|}
\hline Reportagens & $\begin{array}{c}\text { Edição das } \\
\text { revistas }\end{array}$ & $\begin{array}{c}\text { Ano de } \\
\text { publicação }\end{array}$ \\
\hline O charme vai a campo & $\mathrm{N}^{\circ} 738$ & 1984 \\
\hline A mulher, no futebol igualará o homem? & $\mathrm{N}^{\circ} 738$ & 1984 \\
\hline Menina não entra & $\mathrm{N}^{\circ} 873$ & 1987 \\
\hline História da Bola & $\mathrm{N}^{\circ} 1119$ & 1996 \\
\hline Bronze nelas, chumbo neles & $\mathrm{N}^{\circ} 1167$ & 2000 \\
\hline Confissões de uma lateral & $\mathrm{N}^{\circ} 1309$ & 2007 \\
\hline Pelo fim do trauma da prata & Guia olímpico & 2012 \\
\hline Cheias de charme & $\mathrm{N}^{\circ} 1374$ & 2013 \\
\hline Close Nelas & $\mathrm{N}^{\circ} 1396$ & 2014 \\
\hline É Hexa, É Genial, É Marta! & $\mathrm{N}^{\circ} 1444$ & 2018 \\
\hline Surge a rainha Marta, a melhor de todos os tempos & $\mathrm{N}^{\circ} 1447$ & 2019 \\
\hline Marta: A melhor da história & $\mathrm{N}^{\circ} 1457$ & 2019 \\
\hline Quem são as estrelas no Brasil e no mundo? & $\mathrm{N}^{\circ} 1457$ & 2019 \\
\hline A evolução nos últimos 40 anos & $\mathrm{N}^{\circ} 1457$ & 2019 \\
\hline O Sucesso de Corinthians e Ferroviária & $\mathrm{N}^{\circ} 1457$ & 2019 \\
\hline Cristiane, Craque Tricolor & $\mathrm{N}^{\circ} 1457$ & 2019 \\
\hline
\end{tabular}

Fonte: Elaborado pelos autores.

A mulher, na sociedade como um todo, sempre teve que provar sua aptidão para as atividades acadêmicas e profissionais. $O$ pensamento patriarcal atribuiu apenas atividades domésticas para as mulheres, considerando, por muito tempo, elas inaptas para qualquer outro afazer. Com a luta feminista, as mulheres alcançaram o direito de trabalhar, de votar, de praticar esportes, e até mesmo de jogar futebol. No entanto, a igualdade de gênero, em termos de visibilidade, salário e até mesmo tratamento, ainda não é uma luta ganha.

Como o futebol é um reflexo da sociedade, o mesmo acontece nessa área. Até meados da década de 2000, as aparições das atletas na revista PLACAR estavam sempre relacionadas ao seu 
corpo. Era como se sua voz estivesse diretamente ligada à sua beleza, e ela só teria visibilidade dessa forma.

Muitas jogadoras ficavam de fora da mídia por não cumprir os padrões estéticos ou por não querer exibir seus corpos. Os adjetivos de tratamento eram sempre sexistas e pouco falavam das habilidades em campo, mas sim da rotina, gostos e de seu padrão de beleza.

Essas aparições reforçavam o pensamento de que o futebol era para homens, mesmo que mulheres também o praticassem, porque elas não eram vistas nem tratadas como atletas, já que seus jogos não eram exibidos, pouco se sabia sobre seus campeonatos e o destaque era sempre com intuição de objetificar o seu corpo.

"O charme vai a campo" é uma reportagem publicada em julho de 1984 pela revista PLACAR, sendo a primeira capa dedicada ao futebol feminino. Nela encontramos o relato da jogadora Sally, que diz “eu pensava que era a única mulher a jogar futebol”, além de mencionar como a falta de salário atrapalha a chegada das jogadoras a profissionalização. Apesar de ser um marco da conquista por espaço midiático, a capa da revista exibe uma jogadora de calcinha abraçando as pernas, menciona times com jogadoras "feias e bonitas" e termina com uma recomendação de cuidado com os seios.

"Menina não entra", de fevereiro de 1987, conta a histórias de duas irmãs gêmeas de 12 anos que se vestiam de menino para jogar em um time, pois não havia nenhum na cidade. Essa matéria é reflexo da falta de lugar para a mulher no futebol.

“Close nelas" vai contra a maré de objetificação, já que retrata 243 mulheres em imagens relacionadas ao futebol. Isto é, jogando bola na praia, na comunidade, vestidas de freira, na arquibancada e etc.

Em agosto de 2007 a revista PLACAR publicou a entrevista com a jogadora do Mackenzie em uma reportagem intitulada "Confissões de uma lateral". Maíra, de 26 anos, defende que a distinção começa em diferenciar o futebol do futebol feminino, denuncia machismo implicado nas perguntas das pessoas e como ela sempre tem que provar que entende de futebol quando diz que joga. O salário da atleta era de 500 reais na época, ou seja, muito menor do que os rendimentos dos homens que jogavam o esporte de forma profissional.

Até 2011, 28 anos após a regulamentação do futebol feminino, as jogadoras utilizavam o uniforme da seleção masculina. Uma pesquisa feita pelo FiFPro, em parceria com a Universidade de Manchester, com jogadoras de clubes de elite da América, África, Ásia e Europa, descreve que 49,5\% delas não recebem salário. Marta, eleita melhor jogadora do mundo pela FIFA por seis vezes, recorde entre atletas de ambos os sexos, tinha salário de 340.000 euros por ano, enquanto Neymar, sem nenhuma eleição, ganhava 36 milhões de euros por ano, de acordo com o estudo. 
A luta pela igualdade de gênero no futebol também já foi evidenciada em outros estudos na literatura científica. Nesse sentido, Borges et al. (2006) investigaram a existência de comportamento resiliente de meninas que praticam o futebol, tomando como amostra um grupo dejogadoras da classe pobre, praticantes da modalidade em Viçosa-MG.Apesar do interesse pela vivência dessa prática corporal ser equivalente em ambos os gêneros, os autores e autoras identificaram duas dificuldades para a permanência das jogadoras, sendo elas a frequente sujeição ao estereótipo da masculinizaçãoe a necessidade de auxiliar as mães em tarefas domésticas, inviabilizando a participação das jovens em muitas competições. Dessa forma, existem mais barreiras para as meninas permanecerem praticando o futebol feminino, gerando muita resiliência nas jogadoras que sobrevivem a todo esse processo de exclusão.

Balardin et al. (2018) entrevistaram sete atletas brasileiras de futebol, que tenham atuado ou atuam em clubes dos Estados Unidos e do Brasil, com objetivo de analisar as reais condições para a prática do futebol feminino no território brasileiro. Os resultados da pesquisa mostram que as jogadoras brasileiras enfrentam diversas dificuldades, pois os campos são irregulares e os treinos acontecem em parques públicos, porque as prioridades dos campos de clubes são dos atletas do futebol masculino; os alojamentos dos times são precários; as viagens para os jogos são realizadas de ônibus, envolvendo horas de deslocamento; os salários são baixos ou inexistentes e a estrutura de saúde costuma ser muito ruim. Além das péssimas condições para jogar, as meninas, muitas vezes, não possuem apoio da sua família para continuar participando dos treinos e campeonatos.

Portanto, as reportagens publicadas na Revista PLACAR e na literatura científica enfatizam que a luta das atletas que jogam futebol para conseguir sobreviver da modalidade esportiva é gigantesca. Consideramos essa situação inexplicável, principalmente em um país que paga salários milionários para uma parcela dos homens que praticam a modalidade esportiva em competições oficiais.

\section{Jogos e campeonatos femininos de futebol}

Ao longo dos últimos $40 \mathrm{anos}$, em que o futebol feminino foi permitido e reconhecido no Brasil, os times dessa modalidade esportiva compostos por mulheres concorreram em olimpíadas e mundiais. Além disso, as equipes participaram de campeonatos regionais ou de peladas. As matérias que se dedicaram a narrar esses jogos então indicadas abaixo, acompanhadas por suas revistas.

Quadro 4 - Reportagens relacionadas com jogos e campeonatos femininos de futebol 


\begin{tabular}{|c|c|c|}
\hline Reportagens & Edição das revistas & $\begin{array}{c}\text { Ano de } \\
\text { publicação }\end{array}$ \\
\hline As invencíveis & $\mathrm{N}^{\circ} 767$ & 1985 \\
\hline A mulher do ano & $\mathrm{N}^{\circ} 11 . J \mathrm{AN}$ & 2002 \\
\hline O Show das meninas em Toronto & $\mathrm{N}^{\circ} 1405$ & 2015 \\
\hline Ferroviária campeã da América 2015 & $\mathrm{N}^{\circ} 1409$ & 2015 \\
\hline É hexacampeão! & $\mathrm{N}^{\circ} 1410$ & 2016 \\
\hline Elas também conquistaram o coração do Brasil & $\mathrm{N}^{\circ} 1418 \mathrm{~B}$ & 2016 \\
\hline Bola de prata Olímpica & $\mathrm{N}^{\circ} 1418 \mathrm{~B}$ & 2016 \\
\hline Futebol Feminino & $\mathrm{N}^{\circ} 1418$ & 2016 \\
\hline Como são os Campeonatos pelo Mundo? & $\mathrm{N}^{\circ} 1457$ & 2019 \\
\hline O fenômeno no mundial da França & $\mathrm{N}^{\circ} 1457$ & 2019 \\
\hline O futebol raiz do palmeirinha & $\mathrm{N}^{\circ} 1457$ & 2019 \\
\hline
\end{tabular}

Fonte: Elaborado pelos autores.

Do período de 1941 a 1979, o futebol feminino não era permitido por lei, totalizando 38 anos onde a pratica foi proibida no Brasil. Mesmo após esse período de censura, apenas quatro anos depois, em 1983, a pratica obteve regulamentação própria. Uma vez liberado e regulamentado, os campeonatos femininos, apesar de inúmeras dificuldades, gradativamente ganharam cada vez mais força. Os problemas da modalidade estavam relacionados com a falta de salário que, por consequência, limitava o tempo disponível para treino e a indisponibilidade de técnicos, que inviabilizava o aumento do nível técnico das mulheres que participavam desses jogos e campeonatos.

A reportagem "As invencíveis" descreve sobre a aspiração do time Radar em conseguir vencer o Campeonato Mundial de clubes de Futebol Feminino. Essa reportagem foi publicada em 1985. Na época, o time já era bicampeão carioca. Naquele ano, a equipe havia perdido apenas um gol, que foi "ironicamente um gol contra da zagueira Jurema".

Em 2015, a seleção feminina venceu o sexto Torneio Internacional de Futebol Feminino, ocorrência que inspirou a matéria publicada em janeiro de 2016: "É hexacampeão". O placar da final foi de 3x1 contra a seleção canadense. A reportagem é repleta de fotos emocionantes de comemoração, em uma delas as jogadoras Marta e Formiga seguram a taça.

Em 2019, a França sediou o próximo mundial de futebol feminino que foi assistido e admirado mundialmente, por conta da cobertura que a mídia realizou. Em homenagem, a revista 
PLACAR publicou um dossiê do futebol feminino, que além de se desculpar pelo passado machista, possuía cobertura abrangente do evento.

"O futebol raiz do Palmeirinha" é uma reportagem publicada nessa edição especial, que retrata o time do Palmeirinha, formado por meninas da Favela de Paraisópolis. A matéria narra a rotina do time com as dificuldades encontradas. Dentre elas, a falta de dinheiro, de espaço para lazer, os atrasos das meninas e dificuldade de compromisso. A técnica é Mônica Melo da Silva que “impõe algumas regras dignas de times profissionais".

A capitã do Palmeirinha, Camila Rodrigues, não vive mais em Paraisópolis, mas explica que "sai do Campo Limpo para jogar com o maior prazer do mundo". Ela está no time desde sua fundação, e diz a seguinte frase na reportagem. "O esporte tira qualquer pessoa do mau caminho. Eu tive muitas oportunidades de fazer coisa errada, mas o esporte não deixou. Se conseguirmos o apoio para reformar as quadras, imagina a quantidade de crianças que poderão ser salvas"

Em 2019, o Palmeirinha foi finalista da Taça das Favelas, jogo disputado no estádio do Pacaembu, que contou com apresentação da rede globo. Palmeirinha perdeu de 2x0 para o Complexo Casa Verde.

Assim como na Revista PLACAR, pesquisas mais recentes começaram a analisar o jogo de futebol feminino, enfatizando as características dos campeonatos e as questões fisiológicas e táticas que influenciam nas partidas. Dessa forma, apenas nas últimas décadas que a modalidade esportiva praticada pelas mulheres passou a ser realmente reconhecida e estudada na sua essência.

Podemos exemplificar essa realidade em diferentes pesquisas. Costa (2018) descreveu as características do campeonato gaúcho de futebol feminino adulto através das reportagens publicadas pelo jornal Zero Hora, ressaltando a importância de analisar as competições regionais dessa modalidade esportiva. Ainda nesse contexto, Ramos (2018) relatou a história do campeonato brasileiro de futebol feminino e Silveira e Flôres (2018) analisaram a origem dos gols sofridos nessa respectiva competição realizada no ano de 2017, evidenciando a maior competição nacional de futebol jogado por mulheres.

Pesquisas também foram produzidas para analisar as características fisiológicas, bioquímicas, biomecânicas (FELTRIN et al., 2012) e neuromusculares das atletas de futebol feminino (CABISTANY et al, 2018), além dos aspectos fisiológicos e nutricionais aplicados a modalidade esportiva praticada por mulheres (SANTOS; OLIVEIRA; FRANCO, 2019). 


\section{A mulher na área esportiva no futebol}

O futebol é um esporte que exige muitos profissionais trabalhando durante uma partida. Dentre eles, destacam-se os árbitros, bandeirinhas, narradores e jogadores e jogadoras. Todas elas, eram ocupadas majoritariamente por homens. Entretanto, conforme o futebol feminino avançou, os outros campos também o acompanharam. A mulher ganhou lugar em diversas áreas do futebol e essa categoria visa mostrar como ela é vista e tratada nesse meio.

O quadro abaixo mostra as matérias que falam sobre o assunto em pauta, e as revistas que as contém.

Quadro 5 - Reportagens relacionadas com a mulher na área esportiva no futebol.

\begin{tabular}{|c|c|c|}
\hline Reportagens & Edições da revista & $\begin{array}{c}\text { Ano de } \\
\text { Publicação }\end{array}$ \\
\hline Cartola querida & $\mathrm{N}^{\circ} 780$ & 1985 \\
\hline A Juíza Mais Gostosa do Brasil & $\mathrm{N}^{\circ} 1116$ & 1996 \\
\hline O primeiro campeonato de futebol feminino & $\mathrm{N}^{\circ} 1125$ & 1997 \\
\hline começa & & 2005 \\
\hline Uma mulher ajuizada & $\mathrm{N}^{\circ} 1286$ & 2005 \\
\hline A Volta das mulheres & $\mathrm{N}^{\circ} 1286$ & 2009 \\
\hline Me contrata, Presidenta? & $\mathrm{N}^{\circ} 1332$ & 2011 \\
\hline Bandeirinhas Felinas & $\mathrm{N}^{\circ} 1360$ & 2013 \\
\hline As Mulheres na mídia & $\mathrm{N}^{\circ} 1380$ & 2019 \\
\hline
\end{tabular}

Fonte: Elaborado pelos autores.

Como já mencionado anteriormente, em 1979 as mulheres obtiveram permissão por lei para jogar futebol. No entanto, as demais áreas seguiam intocáveis. Os árbitros, narradores, apresentadores, técnicos e cartolas seguiam majoritariamente masculinos.

Em maio de 1985 a revista PLACAR publica a primeira reportagem sobre uma Cartola feminina, Sirlei. Ela comandava o Internacional, antes disso, era advogada. A reportagem elogia o desempenho da mesma, mas encontramos expressões como "Ela preferiu usar argucias femininas [...] e foi chorar na porta da prefeitura e conseguiu um ônibus grátis". Sirlei estava contente no cargo, mas conta que os jogadores costumam trata-la "mais como mulher do que Presidenta". 
Esse tratamento pode ser explicado pelo modo de pensar das pessoas de que apesar de uma mulher estar em um cargo de poder, ela ainda é uma mulher. Logo, é permitido não a levar a sério, ou até mesmo a tratar delicadamente devido ao pensamento de que mulher é frágil.

Essa realidade ainda pode ser vista nos dias atuais e foi apresentada por Oliveira et al. (2019), em um estudo que identificou a participação das mulheres na estrutura organizacional dos clubes de futebol brasileiros. Como resultados, identificou-se a baixa representatividade das mulheres como membros dos órgãos estatutários dos clubes no Brasil, com apenas 3,79\% do total de membros. As autoras e o autor ainda mencionam que inserção feminina na gestão esportiva, ainda que pequena, foi realizada com um processo de alta qualificação dessas profissionais no mundo esportivo.

Outra área que as mulheres também alcançaram foi a da arbitragem. A capa da revista de janeiro de 1996, exibia Cleydi Ribeiro com roupas curtas e um cartão vermelho, e ao lado o título “A juíza mais gostosa do Brasil”. Ao longo da matéria, Cleydi aparece em fotos vestindo um casaco, lingerie, salto alto e batom vermelho. Ao fim, um recorte apenas do corpo da arbitra para começar o título de "Apito Fatal”.

O conteúdo da reportagem é contar como ela é assediada em campo, de sua vida amorosa e etc. Cleidy defende a posição feminina na arbitragem dizendo que "o espetáculo fica muito mais bonito". Além disso, lê-se que "afinal, como prestar atenção na bola com uma loiraça correndo pelo gramado, toda vestida de preto e com um provocante batom vermelho nos lábios", que implica diretamente no pensamento machista de que a beleza feminina pode distrair o homem.

Em setembro de 2005, a revista PLACAR publica uma entrevista com Silvia Regina, arbitra profissional, intitulada "Uma mulher ajuizada". A entrevista fala de seus hábitos, gostos, se esta solteira, disponível e etc. No final de fevereiro do mesmo ano, em um jogo de Corinthians e São Paulo, o qual a Silvia arbitrou, o técnico do Corinthians (Tite) disse "mulher não pode apitar futebol de alto nível. O torque da mulher, a força da muscular e a velocidade dela fazem com que não possa acompanhar os homens". A arbitra convocou uma entrevista coletiva e mostrou dados da Federação Paulista que validavam seu desempenho. Tite foi demitido do cargo, e ela possui o seguinte comentário sobre a situação "o Tite não foi machista, ele usou o argumento que tinha na hora para desviar a atenção da questão técnica.

Essa defesa que muitas mulheres fazem tanto da exposição de seu corpo quanto do questionamento da sua capacidade por serem mulheres, não quer dizer que elas concordam com a situação. Acontece que o senso comum enxerga o machismo como algo hediondo, ao invés de cotidiano. E para não serem enquadradas novamente no sexismo de mulher frágil e insatisfeita, elas aceitam certas coisas para exercerem suas profissões. 
Indo ao encontro das reportagens publicadas pela Revista PLACAR, Calheiro e Oliveira (2018) investigaram a divisão sexual no trabalho de arbitragem, partindo dos marcadores no corpo das profissionais, como raça, sexualidade, classe, território e suas experiências como árbitra. As entrevistas realizadas evidenciaram as desigualdades existentes a partir de um número ínfimo de mulheres que apitam jogos de futebol, bem como menor participação do trabalho de arbitragem em comparação com os homens, enfatizando que o campo futebolístico é organizado em forma de política de gênero, excluindo as mulheres a partir dos seus marcadores indentitários.

Dessa forma, podemos afirmar que embora exista uma maior quantidade de mulheres que trabalham em diferentes áreas relacionadas com o futebol feminino, o preconceito de gênero ainda persiste, se exaltando quando as profissionais são negras e de classes sociais menos favorecidas.

\section{Tematizando o futebol feminino nas aulas de Educação Física Escolar}

A partir do estudo das revistas e da análise das matérias, podemos concluir que a história da mulher no futebol está fortemente marcada pela proibição e discriminação em seu passado. Esse fenômeno, atrelado ao preconceito de gênero na sociedade, causa a grande desigualdade de visibilidade, salário e mérito no futebol masculino e feminino. Apesar disso, graças a inúmeras atletas e aos ideais feministas, as jogadoras estão gradativamente conseguindo espaço e também respeito.

A revista PLACAR, durante 39 anos, sexualizou jogadoras e outras profissionais, restringindo informações sobre seu desempenho, e mostrando apenas conteúdo relacionado a suas aparências e preferências sexuais. No entanto, conforme as décadas mudavam, nota-se grande diferença de conteúdo, de forma que em 2019 é publicado o Dossiê do Futebol Feminino, grande marco para a história da modalidade esportiva e seu tratamento pela mídia.

A produção de conteúdo midiático, principalmente uma revista de alto alcance como a PLACAR, pode influenciar de diversas formas nas mudanças necessárias para a evolução do futebol feminino no Brasil, por isso a importância desse artigo e também da análise comportamento das matérias ao longo da história.

Ao tomar contato com essa produção discursiva, o professor e a professora de Educação Física Escolar pode tematizar o futebol feminino em suas aulas, problematizando com os alunos e alunas as relações de gênero existentes na realização dessa prática corporal, desvelando o seu processo histórico e analisando os discursos que foram produzidos, ao longo dos anos, sobre a participação feminina nas respectiva modalidade esportiva, seja como atleta, árbitra ou gestora. 
Para exemplificar essa possibilidade, os docentes de Educação Física poderiam organizar um documento com as capas publicadas pela revista Placar que versam sobre o futebol feminino, dividir os estudantes em grupos, solicitar a leitura desse material e debater com os jovens do Ensino Médio sobre as temáticas que foram encontradas nesse estudo, tais como a sexualização da mulher no futebol, a luta pela igualdade de gênero nessa modalidade esportiva, a existência de jogos e campeonatos de futebol feminino e as diversas profissões que são ocupadas por mulheres dentro dessa prática corporal.

Após esse debate mais amplo, cada discente seria estimulado a ler uma reportagem específica, que descreve, por exemplo, a história de uma jogadora que foi apresentada de forma machista, um time que lutou por melhores salários, uma competição de futebol feminino organizada nas periferias, atletas que modificaram a realidade dessa modalidade esportiva, o preconceito sofrido pelas árbitras nos jogos, a transmissão do futebol feminino na televisão, dentre outros temas que podem ampliar o pensamento crítico dos estudantes desse ciclo de escolarização.

Seria extremamente relevante que esse debate fosse ampliado nas escolas, para que todos e todas possam conhecer os aspectos históricos, econômicos, sociais e políticos do futebol feminino no Brasil. Dessa forma, uma exposição poderia ser organizada pelos jovens, onde grupos apresentariam textos, imagens, reportagens e entrevistas apresentadas na Revista PLACAR na sua unidade escolar, tendo a possibilidade de pesquisar esse tema em outros veículos de comunicação, na comunidade escolar, entre os familiares e colegas.

Após todo esse processo de investigação e apresentação dos conhecimentos aprendidos para a comunidade escolar, docentes e estudantes pensariam na possibilidade de convidar jogadoras, árbitras, treinadoras, jornalistas e outras mulheres que participam do futebol feminino para fazer uma palestra na escola, efetivando um debate mais amplo sobre esse tema, na perspectiva de desconstruir discursos ingênuos e meramente biológicos que desqualificaram a participação feminina no futebol ao longo da história.

Caso essas amplas problematizações estimulem as jovens, jogos de futebol feminino podem ser realizados nas aulas de Educação Física. Nessa perspectiva, tematizar e problematizar essa prática corporal no Ensino Médio significa ampliar a leitura de mundo sobre os gestos que envolvem essa manifestação da cultura corporal.

Todavia, enfatizamos que esse debate já está acontecendo nas aulas do componente curricular, principalmente porque os docentes de Educação Física passaram a problematizar as relações de gênero que atravessam os esportes, as danças, as lutas, as ginásticas, os jogos e as brincadeiras, a partir dos conhecimentos produzidos pelas Ciências Humanas, ampliando o debate para além do discurso biológico (MALDONADO, 2020). 
Especificamente sobre a tematização do futebol feminino nas aulas de Educação Física, enfatizamos as experiências político-pedagógicas relatadas por Colombero e Gramorelli (2012), Aguiar et al. (2016) e Bonetto (2019), que organizaram diversificadas atividades de ensino para descontruir a ideia que essa prática corporal deve ser realizada apenas por homens.

Portanto, defendemos a ideia de que os professores e as professoras de Educação Física precisam se inspirar em princípios ético-crítico-políticos progressistas para fundamentar a sua prática política-pedagógica, possibilitando que os jovens do Ensino Médio possam fazer uma ampla leitura do mundo sobre os temas históricos, políticos, econômicos, sociais, biológicos e fisiológicos que perpassam as manifestações da cultura corporal (MALDONADO; NOGUEIRA, 2020).

\section{REFERÊNCIAS}

AGUIAR, Alessandra Aparecida Dias et al. Relações de gênero na prática do futebol. In: NEIRA, Marcos Garcia; NUNES, Mario Luiz Ferrari. Educação Física cultural: escritos sobre a prática. Curitiba: CRV, 2016. p. 165-180.

BALARDIN, Geórgia Fernandes et al. O futebol feminino no Brasil e nos Estados Unidos: semelhanças e diferenças no esporte. Revista Brasileira de Futsal e Futebol. São Paulo, v. 10, n. 36, p. 101-109, 2018.

BORGES, Carlos Nazareno Ferreira et al. Resiliência: uma possibilidade de adesão e permanência na prática do futebol feminino. Movimento. Porto Alegre, v. 12, n. 1, p. 105-131, 2006.

BONETTO, Pedro Xavier Russo. Futebol e Copa do Mundo: uma experiência pedagógica baseada na Educação Física Cultural. Revista de Educação Popular. Uberlândia, v. 18, n. 3, p. 109-126, 2019.

CABISTANY, Léo Dutra et al. Características neuromusculares de jogadoras de futebol: estudo com jovens atletas de Pelotas-RS. Revista Brasileira de Futsal e Futebol. São Paulo, v. 10, n. 36, p. 11-17, 2018.

CALHEIRO, Ineildes; OLIVEIRA, Eduardo David. Interseccionalidade no esporte: reflexões sobre o estudo com as árbitras de futebol e o método corpo-experiência.Revista Brasileira de Estudos da Homocultura, v. 1, n. 03 , p. 34-57, 2018

COSTA, Martina Gonçalves Burch. Um olhar sobre o campeonato gaúcho de futebol feminino adulto através das reportagens da gaúcha ZH. Revista Brasileira de Futsal e Futebol. São Paulo, v. 10, n. 37, p. 228-234, 2018.

FELTRIN, Murilo Bortotolloti et al. Caracterização de praticantes de futebol feminino no Brasil. Revista Brasileira de Futsal e Futebol. São Paulo, v. 4, n. 12, p. 151-161, 2012.

FLICK, Uwe. Introdução à pesquisa qualitativa. $3^{\mathrm{a}}$ ed. Porto Alegre: Artmed, 2009.

FRANZINI, Fábio. Futebol é "coisa para macho"? Pequeno esboço para uma história das mulheres no país do futebol. Revista Brasileira de História. São Paulo, v. 25, n. 50, p. 315-328, 2005.

GOELLNER, Silvana Vilodre. Mulheres e futebol no Brasil: entre sombras e visibilidades. Revista Brasileira de Educação Física e Esporte. São Paulo, v. 19, n. 2, p. 143-151, 2005. 
COLOMBERO, Rose Mary Marcos Papolo; GRAMORELLI, Lilian Cristina. Futebol e representações sociais na escola. In: NEIRA, Marcos Garcia; LIMA, Maria Emilia; NUNES, Mário Luiz Ferrari. Educação Física e culturas: ensaios sobre a prática. São Paulo: FEUSP, 2012. p. 31-48.

LAVILLE, Christian; DIONNE, Jean. A construção do saber: manual de metodologia da pesquisa em Ciências Humanas. Porto Alegre: Artes Médicas; Belo Horizonte: UFMG, 1999.

MALDONADO, Daniel Teixeira. Professores e professoras de Educação Física progressistas do mundo, uni-vos! Curitiba: CRV, 2020.

MALDONADO, Daniel Teixeira; NOGUEIRA, Valdilene Aline. Educação Física no Ensino Médio: experiências educativas inspiradas pelos ensinamentos freireanos. Caderno de Educação Física e Esporte. v. 18, n. 1, p. 1-6, 2020.

MOURÃO, Ludmila; MOREL, Marcia. As narrativas sobre o futebol feminino: o discurso da mídia impressa em campo. Revista Brasileira de Ciências do Esporte. Campinas, v. 26, n. 2, p. 73-86, 2005.

NEIRA, Marcos Garcia. Etnografando a prática de skate: elementos para o currículo da Educação Física. Revista Contemporânea de Educação. v. 9, n. 18, p. 299-316, 2014.

OLIVEIRA, Monique Crisitane et al. A Representatividade Feminina na Estrutura Organizacional dos Clubes de Futebol Brasileiros. Anais do XIX USP InternationalConference in Accounting. São Paulo, 2019.

RAMOS, Suellen dos Santos. Campeonato brasileiro de futebol feminino. In: ANJOS, Luiza Aguiar. Resenhar de arquibancada: publicações do GRECCO no ludopédio. Porto Alegre: Centro de Memória do Esporte, 2018. p. 14-19.

SALVINI, Leila; MARCHI JÚNIOR, Wanderley. Registros do futebol feminino na Revista Placar: 30 anos de história. Motrivivência. v. 28, n. 49, p. 99-113, 2016.

SANTOS, Daniel; OLIVEIRA, David Michel; FRANCO, Gabriel. Aspectos fisiológicos e nutricionais aplicados ao futebol feminino. Revista Brasileira de Futsal e Futebol. São Paulo, v. 11, n. 43, p. 279-290, 2019.

SILVEIRA, Thaís Cristina Weiss; FLÔRES, Fábio Saraiva. Análise dos gols sofridos no campeonato brasileiro feminino de futebol. Revista Brasileira de Futsal e Futebol. São Paulo, v. 10, n. 37, p. 202-208, 2018.

SOUZA, Juliana Sturmer; KNIJNIK, Jorge Dorfman. A mulher invisível: gênero e esporte em um dos maiores jornais diários do Brasil. Revista Brasileira de Educação Física e Esporte. São Paulo, v. 21, n. 1, p. 35-48, 2007.

SOUZA, Maria Thereza Oliveira; CAPRARO, André Mendes; MORAES e SILVA, Marcelo. Habilidosas e bonitas: as considerações de duas atletas de futebol sobre a formação das suas identidades. Movimento. Porto Alegre, v. 23, n. 3, p. 883-894, 2017.

TEIXEIRA, Fábio Luís Santos; CARMINHA, Iraquitan de Oliveira. Preconceito do futebol feminino brasileiro: uma revisão sistemática. Movimento. Porto Alegre, v. 19, n. 1, p. 265-287, 2013. 


\section{NOTAS DE AUTOR}

\section{AGRADECIMENTOS}

Agradecemos ao Instituto Federal de São Paulo.

CONTRIBUIÇÃO DE AUTORIA - Não se aplica.

FINANCIAMENTO - Não se aplica.

CONSENTIMENTO DE USO DE IMAGEM - Não se aplica.

APROVAÇÃO DE COMITÊ DE ÉTICA EM PESQUISA - Não se aplica.

CONFLITO DE INTERESSES - Não existe conflito de interesses.

\section{LICENÇA DE USO}

Os autores cedem à Motrivivência - ISSN 2175-8042 os direitos exclusivos de primeira publicação, com o trabalho simultaneamente licenciado sob a Licença Creative Commons Attribution Non-Comercial ShareAlike (CC BY-NC SA) 4.0 International. Esta licença permite que terceiros remixem, adaptem e criem a partir do trabalho publicado, desde que para fins não comerciais, atribuindo o devido crédito de autoria e publicação inicial neste periódico desde que adotem a mesma licença, compartilhar igual. Os autores têm autorização para assumir contratos adicionais separadamente, para distribuição não exclusiva da versão do trabalho publicada neste periódico (ex.: publicar em repositório institucional, em site pessoal, publicar uma tradução, ou como capítulo de livro), com reconhecimento de autoria e publicação inicial neste periódico, desde que para fins não comerciais e compartilhar com a mesma licença.

\section{PUBLISHER}

Universidade Federal de Santa Catarina. Programa de Pós-Graduação em Educação Física. LaboMídia - Laboratório e Observatório da Mídia Esportiva. Publicado no Portal de Periódicos UFSC. As ideias expressadas neste artigo são de responsabilidade de seus autores, não representando, necessariamente, a opinião dos editores ou da universidade.

\section{EDITORES}

Mauricio Roberto da Silva, Giovani De Lorenzi Pires, Rogério Santos Pereira.

\section{EDITOR DE SEÇÃO}

Rogério Santos Pereira.

\section{REVISÃO DO MANUSCRITO E METADADOS}

João Caetano Prates Rocha; Keli Barreto Santos.

\section{HISTÓRICO}

Recebido em: 03 de maio de 2020.

Aprovado em: 26 de outubro de 2020. 